\title{
FUNCTIONAL PHYSICAL FITNESS IN 7-10-YEAR-OLD SCHOOL CHILDREN IN LITHUANIA. PILOT STUDY
}

\author{
Brigita Miežienė ${ }^{1}$, Vida Janina Česnaitiené ${ }^{1}$, Arūnas Emeljanovas ${ }^{1}$, Ingun Fjortoft' ${ }^{2}$, \\ Lise Kjønniksen $^{2}$, Rasa Kreivyte் ${ }^{1}$, Ilona Tilindiené $\dot{e}^{1}$, Kristina Zaičenkovien $\dot{e}^{1}$ \\ Lithuanian sports university ${ }^{l}$, Kaunas, Lithuania \\ University College of Southeast Norway', Notodden, Norway
}

\begin{abstract}
Background. Physical fitness in childhood is a marker of health as it reflects the functional status of most the body functions involved in the performance of daily physical activity and/or physical exercise. Measurement and monitoring of these indicators of health beginning from early age is of highest importance. So, the aim of this study is to examine physical fitness in primary school children and test the validity of physical fitness test battery.

Methods. A sample of 415 children participated in the study. Physical fitness was measured by the 9 -item test battery (Fjørtoft et al., 2011). ANOVA results show that indicators of physical fitness differ across age. In general, older children are more physically fit than the younger ones. Mastering preschool and primary school children's physical fitness evaluation techniques will allow monitoring the changes in physical fitness in the course of the school year in different age groups.

Results. In this study we presented the baseline data of a longitudinal study of 7-10-year-old children in Lithuanian schools. We found a development of achievements in physical functional physical activity across age, the 9-10 years olds being the fittest. We found a pronounced gap in the performance between the age groups of 8-9 years, while the 7-8-year-olds seemed to be more even in their functional fitness competency. The same achievement pattern also was characteristic of boys and girls. Gender differences were found in one test item only (throwing tennis ball), which was explained by different play cultures in boys and girls.

Conclusion. Our results indicate a stronger focus on the modernization of physical education programs for children in this age group, particularly for the 8-year-olds. The PE programs should be based on a multivariate sample of basic motor skills of all ages aiming at developing the children's overall functional physical fitness.
\end{abstract}

Keywords: functional fitness; primary schoolchildren; physical activity.

\section{INTRODUCTION}

$\mathrm{P}$ hysical fitness and physical activity have been identified as important markers in health, both in children and adolescence as it reflects the functional status of most the body functions (skeletomuscular, cardiorespiratory, hematocirculatory, psychoneurological and endocrinemetabolic) involved in the performance of daily physical activity and/or physical exercise (Hallal, 2006; Ortega, Ruiz, Castillo, \& Sjöström, 2008).

Motor competence has been considered as a possible determinant of children's physical activity.
Several studies emphasize the level of motor competence as a common indicator of participation in physical activities that promote positive health outcomes (Cantell \& Crawford, 2008, Fisher et al., 2005). Some studies also indicate that children with motor learning difficulties had significant higher body mass index (Bovet, Auguste, \&Burdette, 2007).

Some researchers argue that the skill-learning gap among children with movement difficulties and their peers increases when they become older because the latter group generally achieve a higher 
level of motor competence and begin to participate in more physical activity tasks. Children with high motor competence (HMC) may find it easier to participate in physical activity, whereas children with low motor competence might choose a more sedentary lifestyle because of their motor problems (Okely, Booth, \& Patterson, 2001; Wrotniak, Epstein, Dorn, Jones, \& Kondilis, 2006). Identification of children at risk for developing a low level of fitness may therefore be relevant so that preventive strategies on global and Governmental level can be applied at an early stage (WHO 2010).

Physical activity habits that are established during childhood tend to track into adulthood more in girls than in boys. School physical education programs seem to be important means in this process (Kjønniksen, Fjørtoft, \& Wold, 2009).

A Norwegian study by Haga (2009) concluded that both the group of children of low motoric competence (LMC) and that of the children of high motoric competence (HMC) scored significantly higher on the physical fitness test after an intervention period of 3.2 months. The lack of a significant interaction effect indicated that the relative differences in physical fitness outcomes between the groups were relatively constant over time. This means that children with low motoric competence (LMC) were likely to have poor physical fitness compared with children with high motoric competence (HMC) during time. These results are interesting both concerning current health status and health status later in those children with low motoric competence. What about the consequences of this and the implications?

Another study by Vedul-Kjelsås, Sigmundsson, Stensdotter, \& Haga (2012) assessed motor competence in 67 sixth- graders boys and girls and possible gender differences. No differences were found in this study in the total score between girls and boys. The researchers conclude that schools might be a good arena for developing appropriate motor skills as a possible contribution to further physical activity later. This is an interesting finding, as most other studies find gender differences in motoric competence in boys and girls (Chen, 2013).

The aim of the present study was to conduct a longitudinal assessment of functional physical fitness in a large sample of healthy boys and girls aged from 7 to 10 years in Lithuanian schools. More specifically, age- and sex-specific differences in physical fitness (i.e., agility, endurance, muscular power, speed, coordination) were quantified by test items and total scores. It was hypothesized that physical fitness would improve from 7-10 years of age and that sex-specific differences would occur over time.

The results from this study may help schools and teachers in the modernization of physical education programs in Lithuanian schools.

\section{METHODS}

Participants. The study included 8 Lithuanian primary schools (5 in Kaunas region and 3 in Kaunas city). A mixed sample of 415 children (204 girls and 211 boys) participated in the study. The research was approved by Lithuanian Bioethics Committee ( $\mathrm{N}^{\circ}$ BE-2-42). Children were allowed to participate only if parental permission was obtained and had to be healthy as well as admitted to physical education classes. The tests were conducted by the qualified researchers who had graduated from physical education (Master or $\mathrm{PhD}$ degree) degree programme and had the training at the University College of Southeast Norway, where the tests were originally created (Fjørtoft Pedersen, Sigmundsson, \& Vereijken, 2011). One participant was excluded as most of his test results were outliers (exceeded three standard deviations). Participants were 7-10 years of age. They performed all tests wearing gym attire.

The distribution of the children across the age groups and the anthropometric measures of height, weight, and body mass index are presented in Table 1 .

\begin{tabular}{|c|c|c|c|c|c|c|c|c|}
\hline \multirow{2}{*}{$\begin{array}{c}\text { Age } \\
\text { group (Y) }\end{array}$} & \multirow{2}{*}{$\begin{array}{c}\text { Total No. of } \\
\text { children }\end{array}$} & \multirow{2}{*}{$\begin{array}{c}\text { No. of } \\
\text { Girls/Boys }\end{array}$} & \multicolumn{2}{|c|}{ Height (cm) } & \multicolumn{2}{c|}{ Weight (kg) } & \multicolumn{2}{c|}{ Body Mass Index (kg/m $\left.\mathbf{m}^{2}\right)$} \\
\cline { 5 - 9 } & & & $\boldsymbol{x}$ & $\boldsymbol{S D}$ & $\boldsymbol{x}$ & $\boldsymbol{S D}$ & $\boldsymbol{x}$ & $\boldsymbol{S D}$ \\
\hline 7 & 127 & $63 / 64$ & 128.3 & 5.81 & 26.62 & 5.37 & 16.10 & 2.33 \\
\hline 8 & 122 & $64 / 58$ & 133.9 & 6.56 & 29.40 & 5.45 & 16.42 & 2.17 \\
\hline 9 & 108 & $51 / 57$ & 139.4 & 6.17 & 34.80 & 6.09 & 17.83 & 2.19 \\
\hline 10 & 57 & $26 / 31$ & 144.6 & 7.66 & 37.16 & 9.15 & 17.62 & 3.40 \\
\hline
\end{tabular}

Table 1. Characteristics of participating children 
The numbers of participating children were evenly distributed across age and gender, except for the 10-year-olds with relative low participation. Body composition in height, weight and BMI was in normal range (www.nhi.no).

Test Items and Materials. Physical fitness was measured by the 9-item test battery, developed by Fjørtoft and colleagues and described in details elsewhere (Fjørtoft et al., 2011). The test battery included the following tests: standing broad jump, jumping a distance of $7 \mathrm{~m}$ on 2 feet, jumping a distance of $7 \mathrm{~m}$ on one foot, throwing a tennis ball with one hand, pushing a medicine ball with 2 hands, climbing wall bars, performing a $10 \times 5 \mathrm{~m}$ shuttle run, running $20 \mathrm{~m}$ as fast as possible, and performing a reduced Cooper test (6 minutes), measuring explosive power, leg muscle power, arm muscle power, upper body power, coordination, agility, speed and endurance. These tests represent typical everyday activities for children, namely, jumping, throwing, climbing, and running (Fjørtoft et al., 2011).

Procedure. Test procedures, described in details elsewhere (Fjørtoft et al., 2011), were explained and each child was tested individually. Each test item was demonstrated before testing. The 3 running tests were performed twice and the better attempt scored. If a procedural error was made by a child, instructions were repeated, and the child made a new attempt. After a second procedural error or when a child could not perform the test item, the test item was scored as missing. The overall score of total fitness was calculated in accordance with the procedure described in Fjørtoft et al. (2011).

Statistical analysis was performed using Statistics V.19.0 for Windows (SPSS, Chicago, Illinois, USA). Data were tested for normality using box plot graph analysis for each age group separately. Values outside the interval of \pm 3 SDs (outliers) were excluded from further analysis. Analysis of variance (ANOVA) was used to compare differences in physical fitness between the age groups with Bonferroni correction for multiple comparisons. Student t test evaluated differences in physical fitness between gender groups. The relationship among test items and association with the total fitness score was calculated using Pearson correlation coefficient. A $p$ value of $<.05$ was considered statistically significant.

Role of the Funding Source. This work was commissioned and supported by the The EEA Grants and Norway Grants.

\section{RESULTS}

ANOVA results using Bonferroni correction presented in Table 2 show that indicators of physical fitness differ across age. In general, older children are more physically fit than the younger ones. The indicators of explosive power (Standing broad jump) significantly differs among all ages $(p<.05)$, but indicators of agility and speed (Shuttle run, Running $20 \mathrm{~m}$ as fast as possible,) do not significantly differ between 7- and 8-year-old and 9- and 10-year-old children. Leg muscle power, measured by jumping a distance of $7 \mathrm{~m}$ on 2 feet of nine-year-old is higher than that in 7-year-old children, but similar to the one in 8 and 10 -yearold. Leg muscle power measured by both jumping tests in 7-year-olds is different than in any other age group $(p<.05)$. Arm muscle power (Throwing a tennis ball) of 7-year-olds significantly differs from that in other age groups, the same indicator in 10-year-olds differs only from that of 7-yearolds. Indicators of upper body power (Pushing a medicine ball of $1 \mathrm{~kg}$ ) do not differ between 8 - and 9-year-olds. Indicators of endurance (Reduced Cooper test) are significantly better in 10-yearolds than those in any other age group, but are not significantly different among 7- and 8-9-years-olds. Differences were also significant in coordination (Climbing up wall bars), 10-year-olds performed significantly better and all other age groups, but indicators of coordination between 7 and 8 -yearold and between 8 and 9-year-old did not differ significantly.

Results in the Table 3 show that indicators of physical fitness are not significantly different between genders, except for pushing the medicine ball test indicator. Boys performed better in this test than girls $(p<.05)$.

Coefficients of Pearson correlation among total fitness scores and individual test indicators presented in Table 4 showed that all eight individual tests correlated positively with the total fitness, with correlations ranging from .289 to .699 , however differently: Standing broad jump $(\mathrm{cm})$ and Jumping a distance of $7 \mathrm{~m}$ on 2 feet (s) had high correlations, though Pushing a medicine $1 \mathrm{~kg}(\mathrm{~m})$ and Shuttle run $10 \times 5$ (s) had low correlations with the total fitness. Correlations between indicators on individual tests items ranged from low to high (.189-.640). Indicators of Climbing up wall bars (s) and Standing broad jump $(\mathrm{cm})$ were not correlated $(p>.05)$. 


\begin{tabular}{|c|c|c|c|c|c|c|}
\hline \multirow{2}{*}{ Test Item } & \multirow{2}{*}{$\begin{array}{c}\text { Age } \\
\text { groups }\end{array}$} & \multicolumn{2}{|c|}{ Test Score } & \multirow{2}{*}{ Min. } & \multirow{2}{*}{ Max. } & \multirow{2}{*}{$p$} \\
\hline & & $x$ & $S D$ & & & \\
\hline \multirow{4}{*}{$\begin{array}{l}\text { Standing broad } \\
\text { jump }(\mathrm{cm})\end{array}$} & 7 & 117.65 & 19.32 & 77.00 & 181.00 & $p^{\mathrm{b}, \mathrm{c}, \mathrm{d}}<.05$ \\
\hline & 8 & 125.50 & 22.94 & 85.00 & 185.00 & $p^{\mathrm{a}, \mathrm{c}, \mathrm{d}}<.05$ \\
\hline & 9 & 142.98 & 22.51 & 83.00 & 190.00 & $p^{\mathrm{a}, \mathrm{b}, \mathrm{d}}<.05$ \\
\hline & 10 & 158.65 & 29.47 & 110.00 & 200.90 & $p^{\mathrm{a}, \mathrm{b}, \mathrm{c}}<.05$ \\
\hline \multirow{4}{*}{$\begin{array}{l}\text { Jumping a distance of } \\
7 \mathrm{~m} \text { on } 2 \text { feet (s) }\end{array}$} & 7 & 3.89 & 0.68 & 2.66 & 6.88 & $p^{\mathrm{b}, \mathrm{c}, \mathrm{d}}<.05$ \\
\hline & 8 & 3.66 & 0.65 & 2.41 & 6.28 & $p^{\mathrm{a}, \mathrm{d}}<.05$ \\
\hline & 9 & 3.48 & 0.64 & 2.14 & 5.40 & $p^{\mathrm{a}}<.05$ \\
\hline & 10 & 3.27 & 0.90 & 2.10 & 6.60 & $p^{\mathrm{a}, \mathrm{b}}<.05$ \\
\hline \multirow{4}{*}{$\begin{array}{l}\text { Jumping a distance of } \\
7 \mathrm{~m} \text { on } 1 \text { foot }(\mathrm{s})\end{array}$} & 7 & 4.01 & 0.66 & 2.53 & 6.42 & $p^{\mathrm{b}, \mathrm{c}, \mathrm{d}}<.05$ \\
\hline & 8 & 3.73 & 0.57 & 2.69 & 5.81 & $p^{\mathrm{a}}<.05$ \\
\hline & 9 & 3.61 & 0.62 & 2.14 & 5.20 & $p^{\mathrm{a}}<.05$ \\
\hline & 10 & 3.49 & 0.81 & 2.30 & 6.45 & $p^{\mathrm{a}}<.05$ \\
\hline \multirow{4}{*}{$\begin{array}{l}\text { Throwing a tennis } \\
\text { ball }(\mathrm{m})\end{array}$} & 7 & 10.11 & 3.67 & 4.00 & 22.00 & $p^{\mathrm{b}, \mathrm{c}, \mathrm{d}}<.05$ \\
\hline & 8 & 12.34 & 3.57 & 5.20 & 22.50 & $p^{\mathrm{a}, \mathrm{c}}<.05$ \\
\hline & 9 & 14.82 & 5.09 & 6.50 & 31.00 & $p^{\mathrm{a}, \mathrm{b}}<.05$ \\
\hline & 10 & 13.97 & 5.26 & 6.00 & 30.00 & $p^{\mathrm{a}}<.05$ \\
\hline \multirow{4}{*}{$\begin{array}{l}\text { Pushing a medicine } \\
\text { ball of } 1 \mathrm{~kg}(\mathrm{~m})\end{array}$} & 7 & 3.05 & 0.80 & 1.40 & 5.44 & $p^{\mathrm{b}, \mathrm{c}, \mathrm{d}}<.05$ \\
\hline & 8 & 3.68 & 1.00 & 2.03 & 7.07 & $p^{\mathrm{a}, \mathrm{d}}<.05$ \\
\hline & 9 & 3.83 & 1.04 & 2.10 & 7.59 & $p^{\mathrm{a}, \mathrm{d}}<.05$ \\
\hline & 10 & 4.44 & 0.97 & 2.40 & 7.36 & $p^{\mathrm{a}, \mathrm{b}, \mathrm{c}}<.05$ \\
\hline \multirow{4}{*}{ Shuttle run 10 x 5 (s) } & 7 & 25.37 & 2.18 & 20.63 & 31.56 & $p^{\mathrm{c}, \mathrm{d}}<.05$ \\
\hline & 8 & 25.11 & 2.55 & 20.80 & 36.93 & $p^{\mathrm{c}, \mathrm{d}}<.05$ \\
\hline & 9 & 23.44 & 2.45 & 18.65 & 29.67 & $p^{\mathrm{a}, \mathrm{b},}<.05$ \\
\hline & 10 & 22.44 & 2.28 & 19.06 & 29.17 & $p^{\mathrm{a}, \mathrm{b},}<.05$ \\
\hline \multirow{4}{*}{$\begin{array}{l}\text { Running } 20 \mathrm{~m} \text { as fast } \\
\text { as possible (s) }\end{array}$} & 7 & 4.98 & 0.53 & 3.85 & 6.15 & $p^{\mathrm{c}, \mathrm{d}}<.05$ \\
\hline & 8 & 5.17 & 0.99 & 3.81 & 8.13 & $p^{\mathrm{c}, \mathrm{d}}<.05$ \\
\hline & 9 & 4.53 & 0.44 & 3.82 & 5.50 & $p^{\mathrm{a}, \mathrm{b},}<.05$ \\
\hline & 10 & 4.30 & 0.39 & 3.64 & 5.20 & $p^{\mathrm{a}, \mathrm{b},}<.05$ \\
\hline \multirow{4}{*}{$\begin{array}{l}\text { Reduced Cooper test } \\
6 \min (\mathrm{m})\end{array}$} & 7 & 783.57 & 139.16 & 523.10 & 1200.50 & $p^{\mathrm{d}}<.05$ \\
\hline & 8 & 750.12 & 178.89 & 350.00 & 1127.00 & $p^{\mathrm{c}, \mathrm{d}}<.05$ \\
\hline & 9 & 838.50 & 149.73 & 510.00 & 1233.00 & $p^{\mathrm{b} ; \mathrm{d}}<.05$ \\
\hline & 10 & 1078.00 & 135.01 & 678.00 & 1345.00 & $p^{\mathrm{a}, \mathrm{b}, \mathrm{c}}<.05$ \\
\hline \multirow{4}{*}{$\begin{array}{l}\text { Climbing up wall } \\
\text { bars (s) }\end{array}$} & 7 & 23.80 & 6.39 & 11.34 & 35.42 & $p^{\mathrm{c}, \mathrm{d}}<.05$ \\
\hline & 8 & 20.28 & 8.15 & 8.06 & 54.01 & $p^{\mathrm{d}}<.05$ \\
\hline & 9 & 19.25 & 6.23 & 9.20 & 39.72 & $p^{\mathrm{a} ; \mathrm{d}}<.05$ \\
\hline & 10 & 12.87 & 7.71 & 5.00 & 37.02 & $p^{\mathrm{a}, \mathrm{b}, \mathrm{c}}<.05$ \\
\hline
\end{tabular}

Table 2. Means, standard deviations, minimum and maximum scores of tests measurements

Note. $a$ - the difference from 7 years; $b-$ the difference from 8 years; $\mathrm{c}$ - the difference from 9 years; $d$ - the difference from 10 years. 
Table 3. Test measurement distribution between boys and girls

\begin{tabular}{|c|c|c|c|c|}
\hline \multirow{2}{*}{ Test Item } & \multirow{2}{*}{ Gender } & \multicolumn{2}{|c|}{ Test Score } & \multirow{2}{*}{$p$} \\
\hline & & $x$ & $S D$ & \\
\hline \multirow{2}{*}{ Standing broad jump (cm) } & Boys & 133.86 & 26.54 & \multirow{2}{*}{$p=.244$} \\
\hline & Girls & 130.76 & 27.17 & \\
\hline \multirow{2}{*}{ Jumping a distance of $7 \mathrm{~m}$ on 2 feet (s) } & Boys & 3.67 & 0.71 & \multirow{2}{*}{$p=.588$} \\
\hline & Girls & 3.63 & 0.71 & \\
\hline \multirow{2}{*}{ Jumping a distance of $7 \mathrm{~m}$ on 1 foot (s) } & Boys & 3.76 & 0.66 & \multirow{2}{*}{$p=.863$} \\
\hline & Girls & 3.77 & 0.66 & \\
\hline \multirow{2}{*}{ Throwing a tennis ball (m) } & Boys & 13.27 & 4.82 & \multirow{2}{*}{$p=.002$} \\
\hline & Girls & 11.82 & 4.49 & \\
\hline \multirow{2}{*}{ Pushing a medicine ball of $1 \mathrm{~kg}(\mathrm{~m})$} & Boys & 3.66 & 0.98 & \multirow{2}{*}{$p=.232$} \\
\hline & Girls & 3.54 & 1.09 & \\
\hline \multirow{2}{*}{ Shuttle run 10 x $5(\mathrm{~s})$} & Boys & 24.15 & 2.83 & \multirow{2}{*}{$p=.125$} \\
\hline & Girls & 24.56 & 2.37 & \\
\hline \multirow{2}{*}{ Running $20 \mathrm{~m}$ as fast as possible (s) } & Boys & 4.84 & 0.73 & \multirow{2}{*}{$p=.856$} \\
\hline & Girls & 4.85 & 0.76 & \\
\hline \multirow{2}{*}{ Reduced Cooper test 6 min (m) } & Boys & 834.59 & 185.90 & \multirow{2}{*}{$p=.479$} \\
\hline & Girls & 820.40 & 192.27 & \\
\hline \multirow{2}{*}{ Climbing up wall bars (s) } & Boys & 19.45 & 8.33 & \multirow{2}{*}{$p=.739$} \\
\hline & Girls & 19.10 & 6.73 & \\
\hline
\end{tabular}

Table 4. Pearson correlation coefficients for total test score and individual tests items

\begin{tabular}{|c|c|c|c|c|c|c|c|c|c|c|}
\hline Test Item & 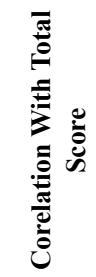 & 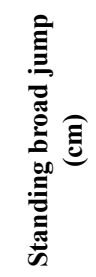 & 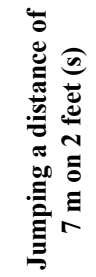 & 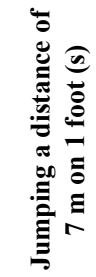 & 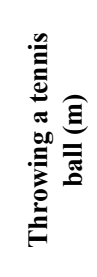 & 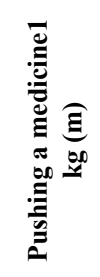 & 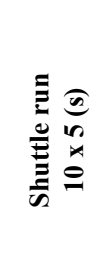 & 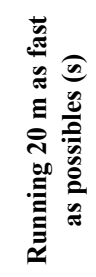 & 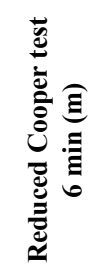 & 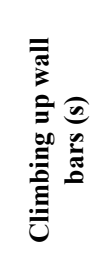 \\
\hline $\begin{array}{l}\text { Standing broad } \\
\text { jump }(\mathrm{cm})\end{array}$ & .699 & 1 & & & & & & & & \\
\hline $\begin{array}{l}\text { Jumping a distance of } \\
7 \mathrm{~m} \text { on } 2 \text { feet }(\mathrm{s})\end{array}$ & .694 & $.543^{* *}$ & 1 & & & & & & & \\
\hline $\begin{array}{l}\text { Jumping a distance of } \\
7 \mathrm{~m} \text { on } 1 \text { foot }(\mathrm{s})\end{array}$ & .467 & $.488^{* *}$ & $.640^{* *}$ & 1 & & & & & & \\
\hline $\begin{array}{l}\text { Throwing a tennis } \\
\text { ball }(\mathrm{m})\end{array}$ & .579 & $.449^{* *}$ & $.467^{* *}$ & $.343^{* *}$ & 1 & & & & & \\
\hline $\begin{array}{l}\text { Pushing a medicine ball } \\
\text { of } 1 \mathrm{~kg}(\mathrm{~m})\end{array}$ & .286 & $.424^{* *}$ & $.382^{* *}$ & $.379^{* *}$ & $.495^{* *}$ & 1 & & & & \\
\hline Shuttle run 10 x $5(\mathrm{~s})$ & .309 & $.542^{* *}$ & $.391^{* *}$ & $.345^{* *}$ & $.252^{* *}$ & $.254^{* *}$ & 1 & & & \\
\hline $\begin{array}{l}\text { Running } 20 \mathrm{~m} \text { as fast as } \\
\text { possible (s) }\end{array}$ & .563 & $.626^{* *}$ & $.548^{* *}$ & $.472^{* *}$ & $.332^{* *}$ & $.189^{* *}$ & $.491^{* *}$ & 1 & & \\
\hline $\begin{array}{l}\text { Reduced Cooper test } \\
6 \mathrm{~min} .(\mathrm{m})\end{array}$ & .386 & $.559^{* *}$ & $.379^{* *}$ & $.272^{* *}$ & $.206^{* *}$ & $.280^{* *}$ & $.402^{* *}$ & $.530^{* *}$ & 1 & \\
\hline $\begin{array}{l}\text { Climbing up wall } \\
\text { bars (s) }\end{array}$ & .313 &, 070 & $.342^{* *}$ & $.394^{* *}$ & $.256^{* *}$ & $.380^{* *}$ & $.185^{* *}$ & $.297^{* *}$ & $.208^{* *}$ & 1 \\
\hline
\end{tabular}

Note. $* *$ - correlation is significant at the .01 level (2-tailed). 


\section{DISCUSSION}

The purpose of the present study was to monitor functional fitness in primary school children in Lithuania. Functional fitness was assessed by using the test "Measuring Physical Fitness in Children who are 5 to 12 Years Old with a Test Battery that is Functional and Easy to Administer (Fjørtoft et al. 2011).

Significant effects of age were detected for all physical fitness tests indicating performance improvements from age $7-10$. The results indicated that older children seemed to be fitter than younger children and the 9-10-year-old children were the fittest. The results were in line with the baseline study of Fjørtoft et al. (2011) and the German longitudinal study (Golle, Muehlbauer, Wick, \& Granacher, 2015). Generally, the results showed that the children's physical fitness increased by age although the differences were not always significant between age groups. However, the total score showed more linear development by age. At the age of 10 children have many different experiences, and thus have developed ,a wide range of competences". The tendency in the results is that physical fitness increases by age, but there are potentials for improving the competencies in each test item by age.

The results also showed that the 10 -year-olds were the fittest concerning endurance (Reduced Cooper test), indicating significantly better results of the 10-year-olds compared to the younger age groups. Differences were also significant in climbing up wall bars, were the 10-year-olds performed significantly better than all other groups. As we already know, physical fitness and motor competence are associated with participation in a wide range of physical activity. The results showed the importance of being physically active in a diverse range of activities, at an early age, especially before 10 years of age. According to Williams et al. (2008), exposure to diverse physical activities is assumed to result in improved motor competence in children.

All test items correlated significantly with each other except for climbing wall bars vs standing broad jump. All test items correlated positively with the total score ranging from 0.286 (pushing medicine ball) to 0.699 (standing broad jump). This corresponded with the findings of Fjørtoft et al. (2011) and indicated that a totality of the results expressed by the total fitness score was a valid expression for the children's functional physical fitness.

In this study we found gender differences in one of the test items only: "Throwing a tennis ball". This corresponded with the findings of the studies by Fjørtoft et al. (2011) and Castro-Piñero et al. (2009). Such gender differences can be explained by cultural differences. In natural games, boys seem to throw more small balls or items than girls. The differences in ball skills in the present study may be due to the different kind of games that boys and girls play. The types of sports and games in which boys and girls choose to participate offer different opportunities for developing motor competence and may contribute to gender differences in later ages (Fjørtoft et al., 2011; Wrotniak et al., 2006).

In practice, this indicates that few gender differences exist in motor competence and physical activity at early ages. Consequently, such results verify the gender equality in games and sports for children less than 10 years of age. For physical education in schools, this should also be a guideline for mixed gender classes.

To be physically active, the mastery of motor performance carrying out a variety of motor activities in childhood is suggested to contribute to further engagement in physical activity in adolescence (Barnett, van Beurden, Morgan, Brooks \& Beard, 2009; Stodden et al., 2008; Wrotniak et al., 2006). This also indicates the value of multifunctional physical activity in early years.

\section{CONCLUSION}

In this study we presented the baseline data of a longitudinal study of 7-10-year-old children in Lithuanian schools. We found a development of achievements in functional physical activity across age, the 9-10-year-olds being the fittest. We found a pronounced gap in performance between the age groups of 8-9 years, while the 7-8-year-olds seemed to be more even in their functional fitness competency. The same achievement pattern also was characteristic of boys and girls. Gender differences were found in one test item only (throwing tennis ball), which was explained by different play cultures in boys and girls. Our first results indicate a stronger focus on the modernization of physical education programs for children in this age group, particularly for the 8-year-olds. The PE programs should be based on a multivariate sample of basic motor skills of all ages aiming at developing the children's overall functional physical fitness. 


\section{REFERENCES}

Barnett, L. M., Van Beurden, E., Morgan, P. J., Brooks, L. O., \& Beard, J. R. (2009). Childhood motor skill proficiency as a predictor of adolescent physical activity. Journal of Adolescent Health, 44(3), 252-259. http://dx.doi.org/10.1016/j.jadohealth.2008.07.004

Bovet, P., Auguste, R., \& Burdette, H. (2007). Strong inverse association between physical fitness and overweight in adolescents: A large school-based survey. International Journal of Behavioral Nutrition and Physical Activity, 4(1), 1. doi: 10.1186/1479-5868-4-24

Cantell, M., \& Crawford, S. G. (2008). Physical fitness and health in dicesin children, adolescents and adults with high or low motor competence. Human Movement Science, 27(2), 344-362.

Castro-Piñero, J., González-Montesinos, J. L., Mora, J., Keating, X. D., Girela-Rejón, M. J., Sjöström, M., \& Ruiz, J. R. (2009). Percentile values for muscular strength field tests in children aged 6 to 17 years: Influence of weight status. The Journal of Strength \& Conditioning Research, 23(8), 2295-2310. https://doi. org/10.1519/JSC.0b013e3181b8d5c1

Chen, A. (2013). Motor skills matter to physical activity - at least for children. Journal of Sport and Health Science, 2(1), 58-59. Retrieved from http://www.sciencedirect.com/science/article/pii/S2095254613000045

Fisher, A., Reilly, J. J., Kelly, L. A., Montgomery, C., Williamson, A., Paton, J. Y., \& Grant, S. (2005). Fundamental movement skills and habitual physical activity in young children. Medicine and Science in Sports and Exercise, 37(4), 684-688. doi: 10.1249/01. MSS.0000159138.48107.7D

Fjørtoft, I., Pedersen, A. V., Sigmundsson, H., \& Vereijken, B. (2011).Measuring physical fitness in children who are 5 to 12 years old with a test battery that is functional and easy to administer. Physical Therapy, 91(7), 1087-1095. https://doi.org/10.2522/ptj.20090350 Golle, K., Muehlbauer, T., Wick, D., \& Granacher, U. (2015). Physical fitness percentiles of German children aged 9-12 years: Findings from a longitudinal study. PloSone, 10(11), e0142393. https://doi.org/10.1371/ journal.pone.0142393

Haga, M. (2009). Physical fitness in children with high motor competence is different from that in children with low motor competence. Physical Therapy, 89(10), 1089-1097. https://doi.org/10.2522/ptj.20090052
Hallal, P. C., Wells, J. C., Reichert, F. F., Anselmi, L., \& Victora, C. G. (2006). Early determinants of physical activity in adolescence: Prospective birth cohort study. British Medical Journal, 332(7548), 1002-1007. https:// doi.org/10.1136/bmj.38776.434560.7C

Henderson, S. E., \& Barnett, A. L. (1992). Movement assessment battery for children. London: Psychological Corporation.

Kjønniksen, L., Fjørtoft, I., \& Wold, B. (2009). Attitude to physical education and participation in organized youth sports during adolescence related to physical activity in young adulthood: A 10-year longitudinal study. European Physical Education Review, 15(2) 139154. http://dx.doi.org/10.1177\%2F1356336X09345231

Okely, A. D., Booth, M. L., \& Patterson, J. W. (2001). Relationship of physical activity to fundamental movement skills among adolescents. Medicine and Science in Sports and Exercise, 33(11), 1899-1904.

Ortega, F. B., Ruiz, J. R., Castillo, M. J., \& Sjöström, M. (2008). Physical fitness in childhood and adolescence: A powerful marker of health. International Journal of Obesity, 32(1), 1-11. https://doi.org/10.1038/ sj.ijo.0803774

Stodden, D. F., Goodway, J. D., Langendorfer, S. J., Roberton, M. A., Rudisill, M. E., Garcia, C., \& Garcia, L. E. (2008). A developmental perspective on the role of motor skill competence in physical activity: An emergent relationship. Quest, 60(2), 290-306. http:// dx.doi.org/10.1080/00336297.2008.10483582

Vedul-Kjelsås, V., Sigmundsson, H., Stensdotter, A. K., \& Haga, M. (2012). The relationship between motor competence, physical fitness and self-perception in children. Child: Care, Health and Development, 38(3), 394-402.

Williams, H. G., Pfeiffer, K. A., O'neill, J. R., Dowda, M., McIver, K. L., Brown, W. H., \& Pate, R. R. (2008). Motor skill performance and physical activity in preschool children. Obesity, 16(6), 1421-1426. http:// dx.doi.org/10.1038/oby.2008.214

Wrotniak, B. H., Epstein, L. H., Dorn, J. M., Jones, K. E., \& Kondilis, V. A. (2006). The relationship between motor proficiency and physical activity in children. Pediatrics, 118(6), e1758-e1765. https://doi. org/10.1542/peds.2006-0742
Corresponding author Vida Janina Česnaitienė

Lithuanian Sports University

Sporto str. 6, Kaunas LT-44221

Lithuania

Tel. +370 37302638

Email vida.cesnaitiene@1su.1t 